\title{
Interrogating Democracy in the Digital Gaze
}

DOI: https://doi.org/10.33008/IJCMR.2020.12 | Issue 4 | June 2020

\section{Carl W. Jones}

University of Westminster/Royal College of Art

https://www.creativemediaresearch.org/post/interrogating-democracy-inthe-digital-gaze

\section{Abstract}

I first started to explore the digital gaze in late 2014 through a video project that later expanded into $7 \times 2$ D large photographic images in 2019. This MultiPiece Portfolio project explores the digital gaze, questions the democracy of Google, and investigates the type of visual registry provided, by asking: Is the digital gaze a Caucasian heterosexual male gaze? Christopher Frayling claims that 'research through art and design' is one of three research methods that artists could select in order to perform academic research. I, however, reverse the name of the method from 'research through art' to 'art through research'. Performed in two phases, the first phase of the Digital Gaze project is academic research that is followed by phase two - the artistic expression informed by the first phase, hence the term 'Art through Research'.

\section{Research Statement}

This Multi-Piece Portfolio project explores the gaze on electronic devices and the type of visual registry it provides. Currently consumers generate inquiries through search engine software, and free applications, whose responses are delivered on electronic devices to the end user. This leads to questions of power, and political economy. Just how democratic is the digital gaze? The research method used is called 'art through research' and is composed of two phases. The first phase investigates theoretically the subject matter using the theories of: Mulvey and the male Gaze; Bernays on propaganda; followed by McLuhan on technology as an extension of man. After reviewing the findings of the theoretical research, a new question arose: Is the digital gaze a Caucasian heterosexual male gaze? Phase two explores this question through the art practice, which involves selecting a word and observing in what respect this word is translated in the digital space. The results of the word search are then visualized in both audio-visual and photographic artefacts. This research statement will guide the reader through the initial theoretical research function that inspired the practice, followed by the significance of each of these artefacts in contributing something distinct to the overriding 
research question and process. What I am presenting to you is the chronological history of this project's research process.

\section{Phase 1: Academic Research}

\section{The Male Gaze}

In 1975, Laura Mulvey published the article 'Visual Pleasure and Narrative Cinema', where she discusses the 'male gaze' and how in Hollywood film before 1975 - the female body was objectified because of male dominance in the movie industry. Mulvey argues that in film, the male gaze is more important than the female gaze and critiques the 'male way' of looking at women and how this gaze was being imposed through the audio-visual medium of film. Reflecting an underlying power imbalance, where the white heterosexual male's gaze is imposed upon the viewer, who could be female, homosexual, or another race, this forced gaze creates an unequal power dynamic where the female viewer sees how the male views the female as an object, and thus can be considered a conscious or unconscious attempt to reenforce that bias. However, in what ways can the male gaze be used to understand today's digital channels?

\section{What is the Digital Gaze?}

I define the 'digital gaze' in terms of how computer-programmed content is distributed to the consumer via free applications, broadcast on electronic devices, for example the internet platform that offers various free services working under the name Google. The 'digital gaze' is the relationship that someone enters through interacting with an electronic device, where the consumer trusts the technology and the solutions it offers. In their book Practices of Looking, Sturken and Cartwright state that 'the gaze is integral to systems of power and ideas about knowledge' (2009: 103). The digital gaze creates a power dynamic where the consumer - in the quest for knowledge allows the electronic device and the software that runs it to give the answers to the questions asked. In 2015, only $18 \%$ of computer science degrees in the USA were those completed by women (NGCP), indicating that Silicon Valley is dominated by men and thus the software that is designed could have the potential for a male gaze. But does the digital consumer receive this male, heterosexual gaze when interacting with a google search?

\section{Electronic Devices as Extensions of Man}

Information and content are broadcast digitally, and in order to access the media the consumer needs to purchase electronic devices. Theorist Marshal McLuhan observed in his book The Medium is the Massage that 'All media are 
extensions of some human faculty - psychic or physical' (2001: 26). Similarly, I consider that mobile phones, tablets and computers can be considered an extension of ourselves, just as 'The wheel is an extension of the foot, the book is an extension of the eye, clothing an extension of the skin, electric circuitry an extension of the central nervous system' (McLuhan, 2001: 26-40). As such, portable electronic devices are an extension of the mind. Consumers are putting such trust in the information delivered by the software that it is beginning to replace memory. For example, contemporary consumers do not memorize phone numbers, because the mobile phone 'remembers' for them, by-way-of software such as android iOS, that is offered for free on electronic hardware. Consumers are growing accustomed to appropriating the information displayed through electronic devices to supplant their own memory. This could allow for biased information to be passed into the consumer's mind, leading to the idea that whoever controls the digital content could control the masses.

\section{Wireless Propaganda Tools}

I will now examine Google through the lens of a propaganda tool, by observing how the UK and US propagandize their ideology, social and cultural values. Propaganda was defined by theorist Edward Bernays, author of the 1928 book Propaganda, who wrote that 'Propaganda is the executive arm of the invisible government' (1928: 48). This observation was put into action through the medium of radio during World War II on both the BBC World Radio, and The Voice of America (VOA), which were offered without charge to the consumer, who received the wireless signals on electronic devices called the radio.

In '1938 the BBC inaugurated foreign-language broadcasts, all in an attempt to combat the totalitarian challenge to democracy' (Welch, 2013). All that was needed was for the audience to have access to the radio. The Internet, like radio, is a technology, which can also reach consumers in any country, regardless of topography, political affiliations and only depends that the consumer/viewer have access to digital computer technology. There are many similarities between the radio services offered by the corporations BBC and Voice of America (VOA), and the web services offered by Google:

- Both radio and Google are services offered free of charge, and broadcast information that the public is searching for;

- Google and radio are broadcast via a wireless signal;

- Both require that the consumer purchase electronic devices to receive the broadcast;

- The BBC and VOA are voices of their respective governments broadcasting western ideology, social and cultural values.

Google is a private corporation that co-operates with the US government by passing information on its users. This we discovered through 'fugitive' 
Edward Snowdon's exposé where he released documents to the press, and the Massachusetts Institute of Technology Review stated that 'U.S. government and law enforcement agencies are increasingly asking Google to hand over data on its customers to help with investigations' (MIT, 2012). According to the newspaper The Washington Post, in 2015 Google was valued at $\$ 65$ billion US dollars (Lyons, 2015), and 'spent $\$ 5.5$ million on lobbying during the first quarter of 2015, the most it has ever spent in one quarter' (Maplight, 2015), convincing the US government to pass certain bills. If this co-operation continues then the question becomes: when will Google stop being considered an independent global corporation, and become a propaganda tool for the US government? In effect, it can be concluded that the digital gaze creates a power dynamic where the consumer - in the quest for knowledge - allows the electronic device and the software that runs it to be used as a propaganda tool. But this leads to a further question: Is the digital gaze a Caucasian heterosexual male gaze?

\section{Phase 2: Art Through Research - The Practice}

\section{The 'Nude' through Google}

Having completed the background academic research outlined above, the next phase of this project was to explore the digital gaze through a video project that later expanded into $7 \times 2$ D large photographic images in 2019. The first thing needed was to create a process that investigated Google's influence in various countries and languages. I created a research method called 'scobo' (Latin for 'search'), which consists of selecting a word and observing in what respect this word is translated in the digital space. The term I chose was 'nude'.

The 'nude' is an important and often used image in the world of art. When humankind started to create artifacts they often began with the human body as a subject. As new technologies were introduced, the creative expression and representation of the nude was affected in its portrayal and interpretation. For this project, the term 'nude' was selected to see how the digital translation is expressed through images that appear on electronic devices.

Google is the world's most valuable brand, because they design free software to collect big data from its users, in order to sell advertising space to corporations. Google offers 'free' apps: Google translate, and nation state specific 'Google.com search' home pages such as https://www.google.ca for Canada, in order to gain data to sell 'targeted messaging capabilities' to advertisers. Christian Fuchs observes that 'Google is the ultimate economic surveillance machine and the ultimate user exploitation machine' (2012: 44). This is achieved through offering services as non-commodities that are not 
sold to consumers but 'rather provided to users without payment' (ibid.). Google's main service is of course its search engine, where the consumer works for free, and the data collected is 'sold as a commodity to advertisers' (ibid.: 45).

\section{The Research Process}

As part of my 'scobo' research process, I selected 7 languages that represented different races, ethnic groups and religions across the globe: English, Russian, Spanish, Chinese, Arabic, Hindu; and Swahili. To do this, I selected countries in different continents that spoke one of these tongues: Russia; Tanzania; Saudi Arabia; Canada; India; China; and Mexico. A limitation for the project was that each of these nation states had to have their own language version of a google search page. One issue I had was google leaving mainland China in $2010-$ (but) not Hong Kong where they continued to offer services - after they (Google) had tried unsuccessfully to work with Chinese censorship authorities (Johnson, 2010). As such, I decided to make Hong Kong the google page that represents China.

Another important research limitation was to change the VPN of the local computer in order for it to appear that the laptop was in fact located within one of the 7 countries, so that the search results would be the same as if the computer was based within that specific nation state. Also, the browser history was erased from the computer so as not to create an influential algorithm or search history that could affect the search results. The process was tested in three different computers in Toronto during December 2014, to see if the same images appeared in the search, and in the same visual order. This was to test if each computer's algorithm and history, or laptop location, affected the search results.

Here are the five steps that I took in order to collect 300 images for each of the 6 searches on google on December 30th 2014, with 1 search of India collected on March 10th 2015.

- Step 1: select 7 languages: English, Russian, Swahili, Chinese, Spanish, Hindi, and Arabic.

- Step 2: select countries that spoke one of the main languages.

- Step 3: place word 'nude' in https://translate.google.com to interpret into one of the 6 other languages; the first word that appears as a translation is then placed into the Google search page representing a country that speaks the language, e.g. for Arabic, the nation state Saudi Arabia as a representative country was selected.

- Step 4: the first 300 images that appear are captured in sequential order through image download. 
- Step 5: create a video for each country of the process and sequential images.

I faced an issue in terms of how to solve Step 5 , as the challenge was to find a way to incorporate the 300 images into a moving image video. This was solved by first creating a keynote presentation of one image per slide placed in chronological order. Then using a keynote feature, I was able to export the 300 images into QuickTime video, that gave each image slightly less than 1 second of screen time.

\section{Video Artefact}

These 7 video artefacts (all available to watch below) were uploaded to Vimeo and gave the audience the ability to see the digital gaze as reflected through a variety of cultures and languages. To date they have been viewed over half a million times on Vimeo platform (2015-2020). On two occasions the videos have been taken down by Vimeo.com as some subscribers have deemed them obscene, and I had to appeal via email, and won by proving they were part of an academic research project. The video format allows the viewer to see the images individually, at a rapid pace, giving the audience an impression of scanning images almost subliminally. The rapid pace at which the visuals are seen gives the sensation of flipping through various TV channels, allowing the audience to see many images in a short amount of time giving them insights into each culture.

Digital Gaze (2014). Video of process and all countries in one. Created by Carl W. Jones.

https://vimeo.com/117691684

Digital Gaze (2014). Saudi Arabia video. Created by Carl W. Jones. https://vimeo.com/116665623

Digital Gaze (2014). China (Hong Kong) video. Created by Carl W. Jones. https://vimeo.com/116665622

Digital Gaze (2014). Russia video. Created by Carl W. Jones. https://vimeo.com/116550404

Digital Gaze (2014). Canada video. Created by Carl W. Jones. https://vimeo.com/116665621

Digital Gaze (2014). Mexico video. Created by Carl W. Jones. https://vimeo.com/116550403 
Digital Gaze (2014). Tanzania video. Created by Carl W. Jones. https://vimeo.com/116550402

Digital Gaze (2014). India video. Created by Carl W. Jones. https://vimeo.com/121811336

\section{Print Exercise}

In 2019, I was challenged to find a way of expressing these video artefacts in a flat printed 2D format, to exhibit the project as part of the Cracking the Established Order conference at De Montfort University. I searched for a simple digital method that was able to show the images in chronological order. I ended up using Photoshop and imported the images and the software placed them automatically in the order that they were collected. This was because when each image was downloaded, the computer automatically dates and assigns the exact time to each image. However, because the images were different sizes and resolutions there sometimes appeared black bars underneath some pictures, as the image did not fill the allotted square photoshop gave (see Fig. 1-7 below). Instead of blowing up each picture to fill its allotted space, I decided to embrace this 'digital glitch' as it was a preprogrammed decision the software had taken, essentially becoming another part of the digital gaze.

\section{Analysis}

In the following section I will analyse each nation state's 300 images as presented in both media forms, as the pictures are the same. While observing the 7 videos and photos one sees how the majority of the images are coded with visual impressions of nude or near naked females, in sexualized positions. Firstly, note how the Russian images below (Fig. 1) present the white, naked female body through well-produced artistic photographs. 


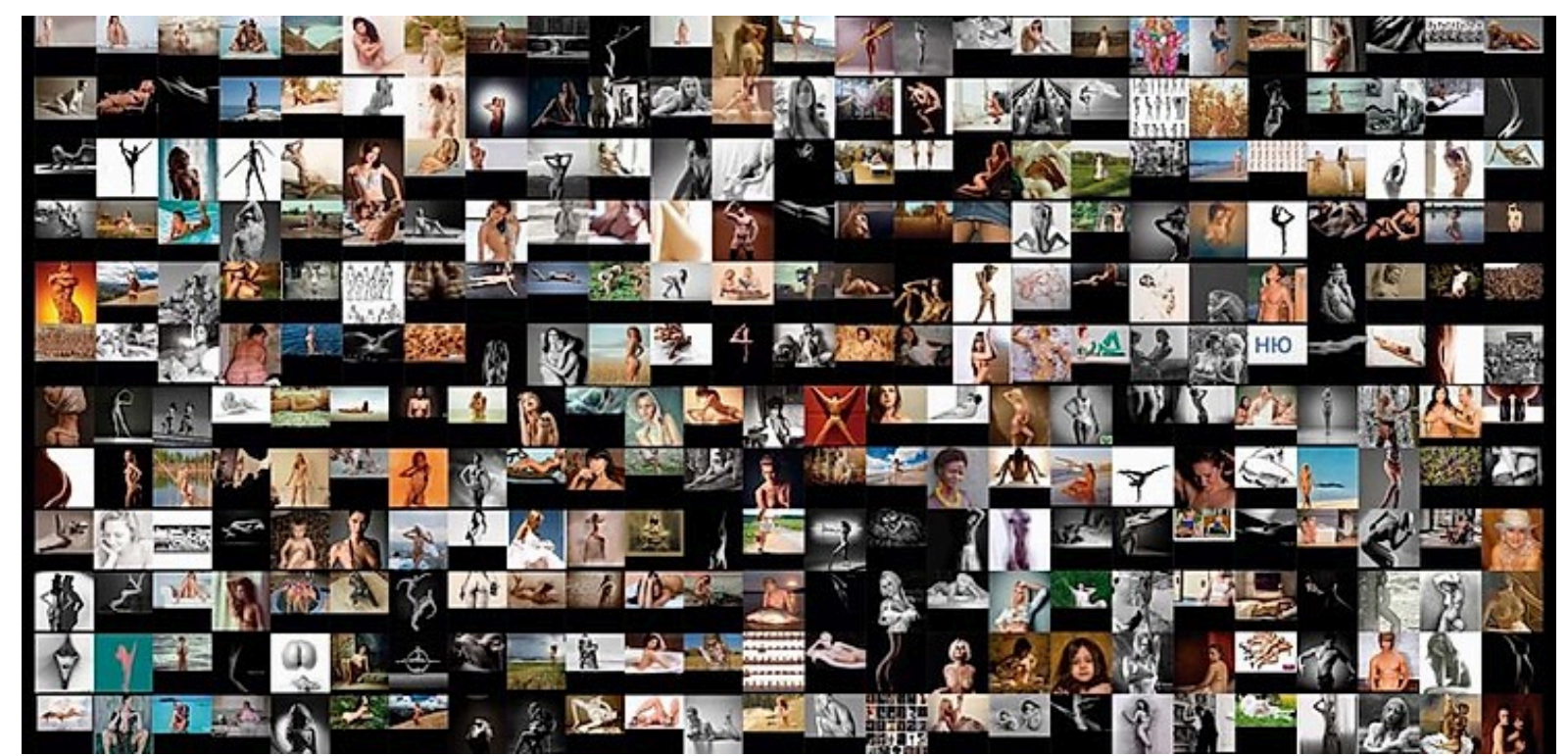

Figure 1: (2019) Russia. Ink on paper $100 \mathrm{~cm}$ x $48 \mathrm{~cm}$.

Saudi Arabia (Fig. 2), meanwhile, displays mostly portraits of suited older males, and the only nudity to appear is a statue, or children playing in sand. One assumes that this is because of being a conservative Muslim country, and also how the word 'nude' was digitally translated using google translate, as the limitations only allowed the first translated word to be searched.

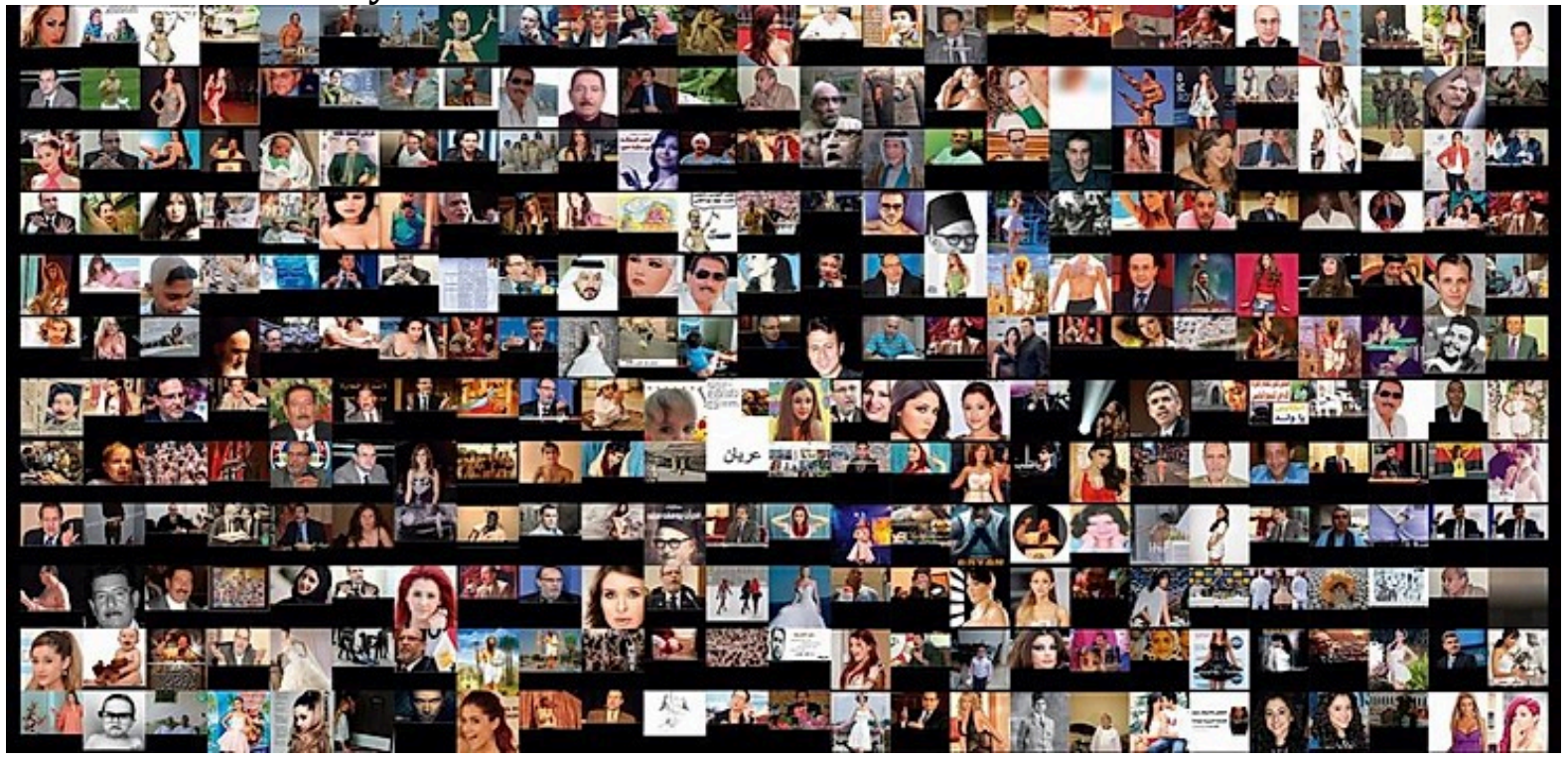

Figure 2: (2019) Saudi Arabia. Ink on paper 100cm x 48cm.

Hong Kong (Fig. 3) displays mostly Asian, with a few Caucasian nude females, all in submissive poses. Some images have the nude body with paint on it, and others are censored with pixels blocking out nipples or pubic hair. 


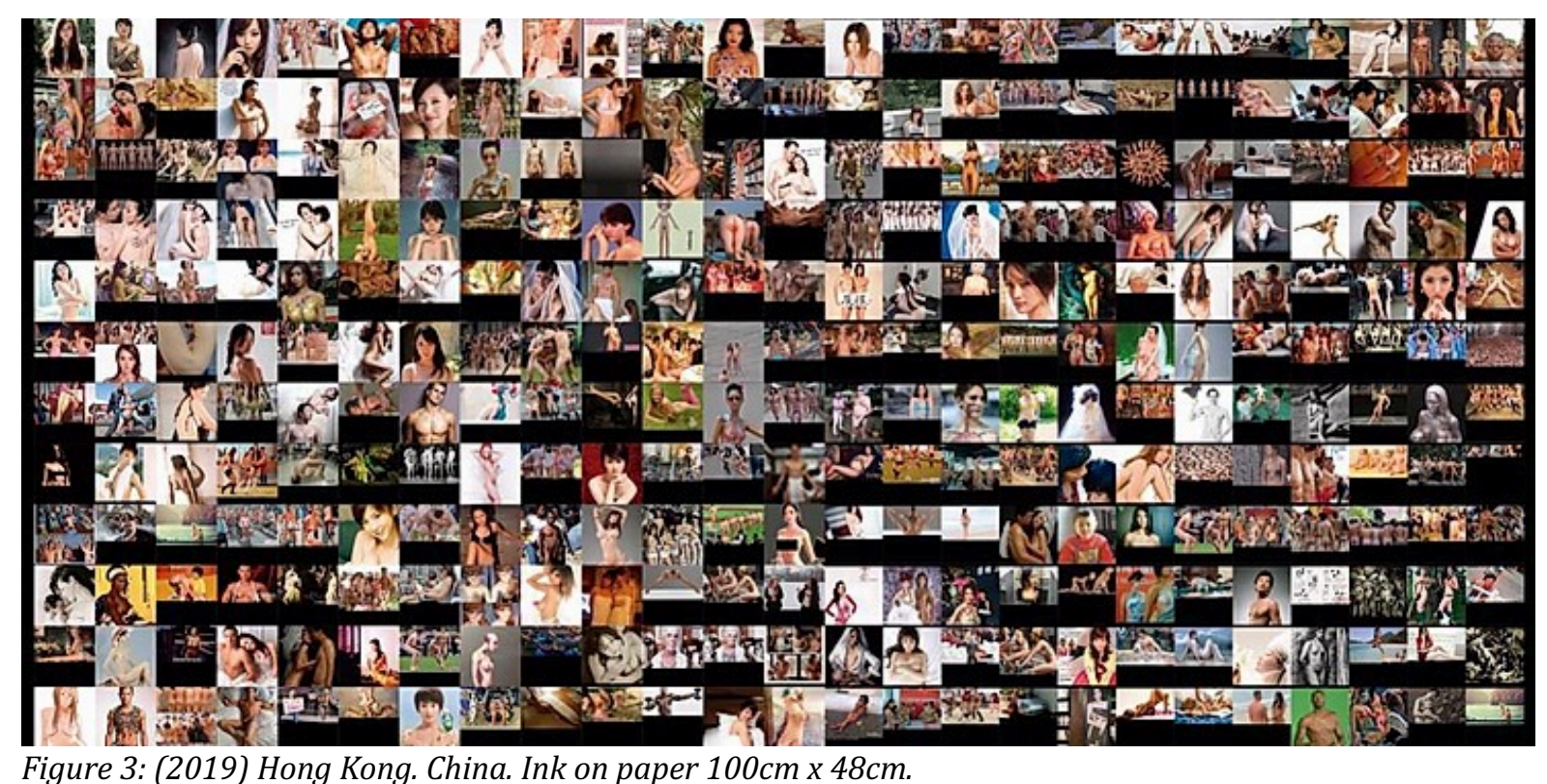

Tanzania (Fig. 4) displays partially nude African females, covered by some form of clothing, with the camera's eye focusing on the buttocks. Some pictures are censored with nipples covered by darkened rectangles.

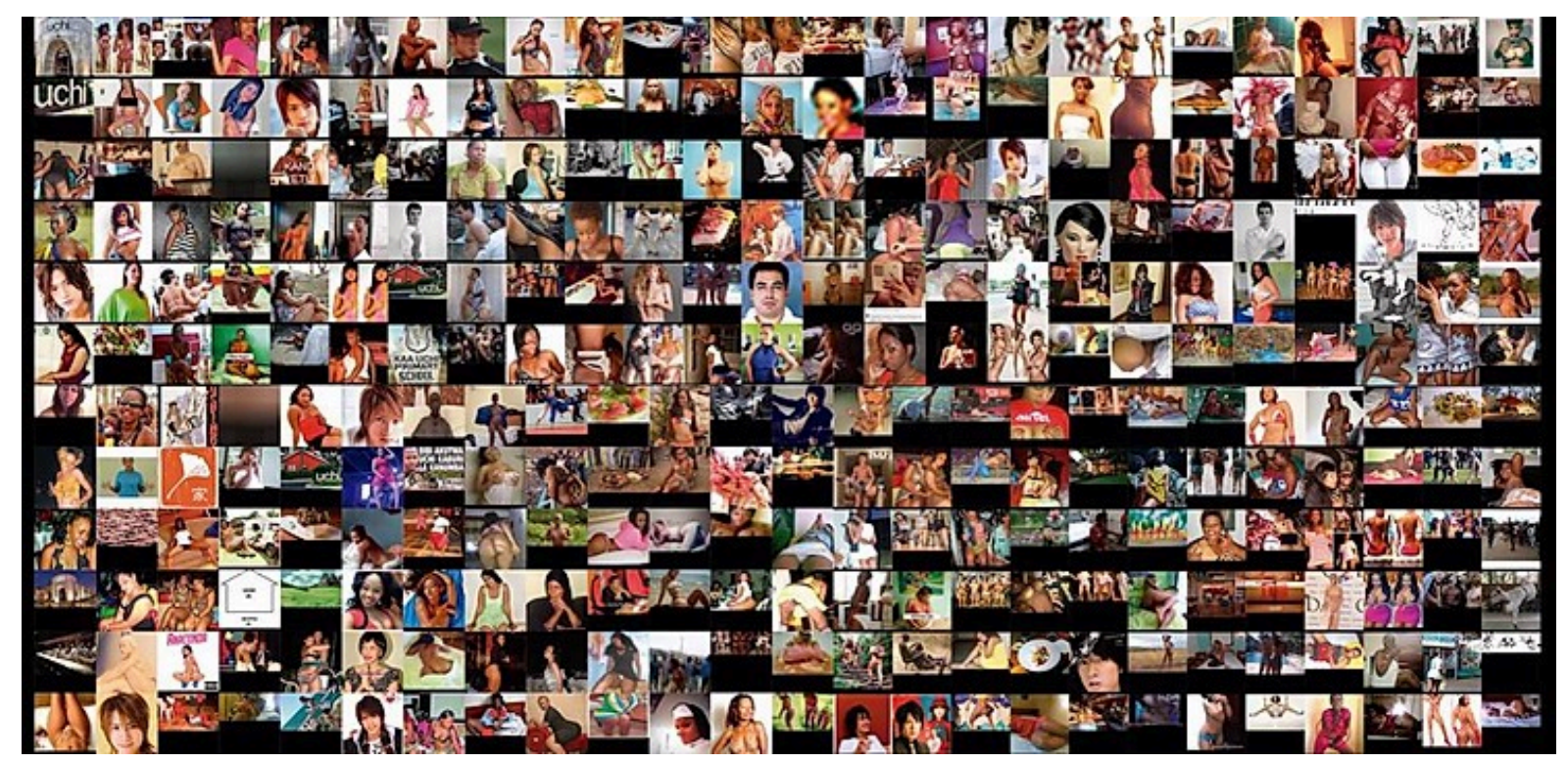

Figure 4: (2019) Tanzania. Ink on paper $100 \mathrm{~cm}$ x $48 \mathrm{~cm}$.

In stark contrast, Mexico (Fig. 5) features $90 \%$ male nudes. This is because of the nature of the experiment that 'selects' the first translated word, which in Spanish is 'desnudo,' and since it ends in 'o' it signifies a gender neutral, and/or 'male' nude. The Mexican nudes presented mostly Caucasian males, some images feature models with coloured skin, and most are objectified sexually. I have recently published research on how advertising in Mexico favours European models over darker skinned or indigenous peoples, and this started over 500 years ago (Jones 2019). The gaze in this Mexican example 
(Fig. 5) is not heterosexual, however it does present a male homosexual gaze, and demonstrates racial and social inequalities in Mexico, while reinforcing colonial thinking. How, though, can the Mexican internet be decolonized?

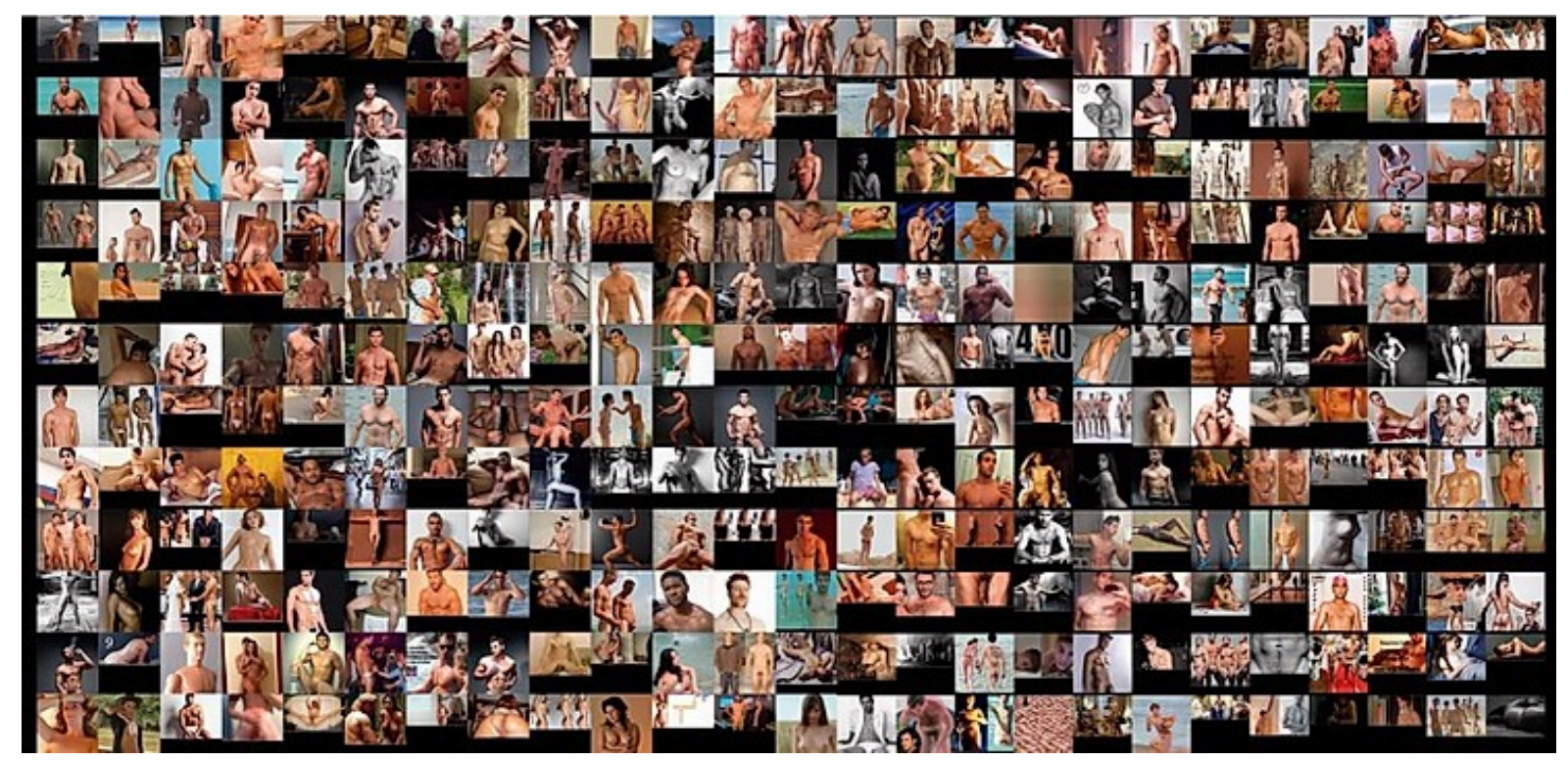

Figure 5: (2019) Mexico. Ink on paper $100 \mathrm{~cm}$ x $48 \mathrm{~cm}$.

India (Fig. 6) presents a collection of Western pornographic images mixed in with local images with 'signs' of violence against women, there are even two images featuring fetal soup. The number of Caucasians reflected in the images is a higher percentage than are in the Indian population. This demonstrates what Couldry and Mejias call a colonization of the digital public sphere (2019).

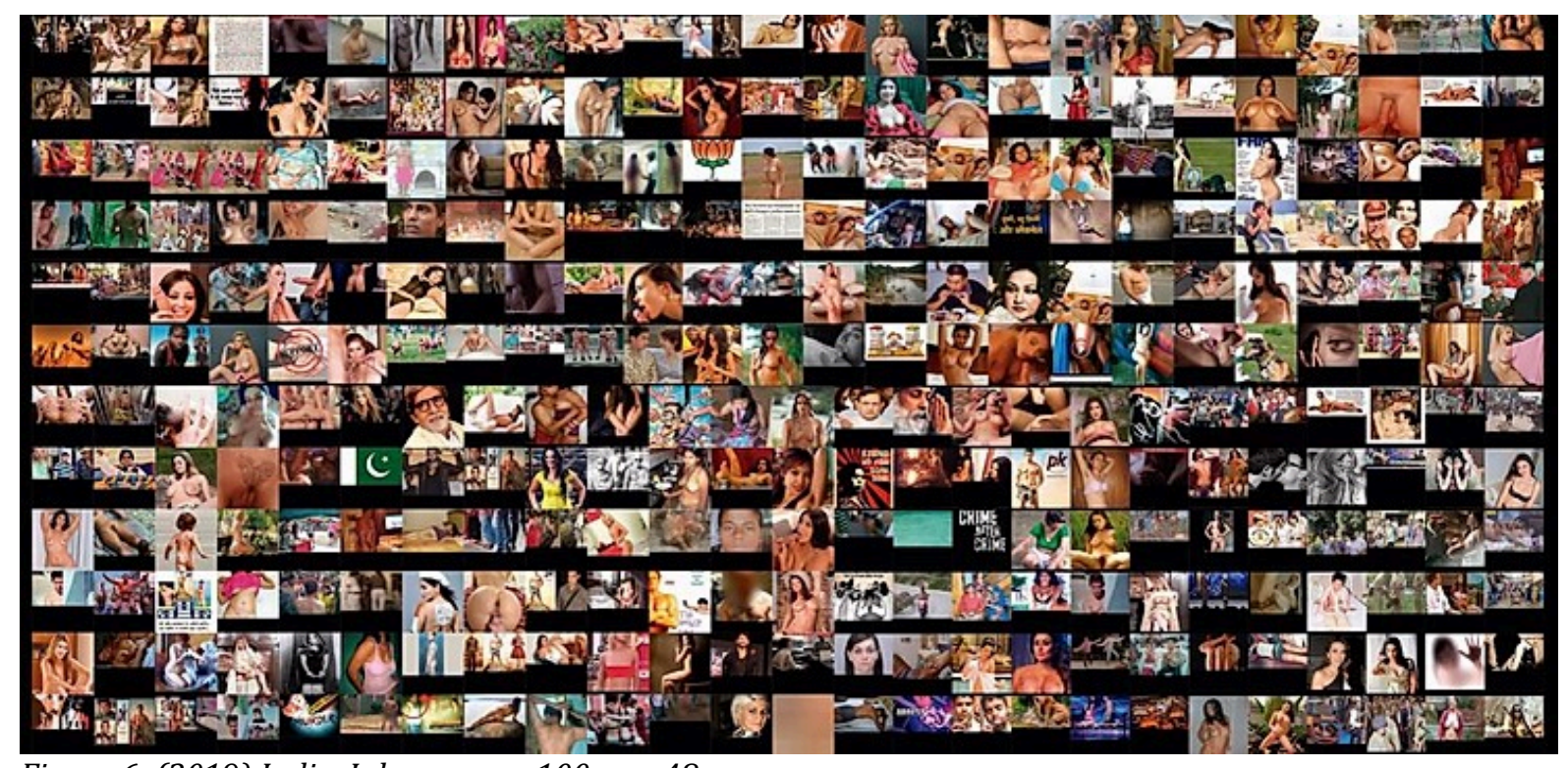

Figure 6: (2019) India. Ink on paper $100 \mathrm{~cm}$ x 48cm. 
Finally, Canada (Fig. 7) displays 300 uncensored coded images of females in sexualized positions, displaying mostly shaved genitalia. Mulvey's male gaze theory can be applied here where the female body is objectified through the medium of photography, demonstrating the idea that the male gaze is more important than the female gaze. Interesting to note, however, that the word 'nude' in English is gender neutral, but in Canada according to Google search the nude is overwhelmingly female. Canada was the only country to represent women of different races from around the world, however the majority are Caucasian.

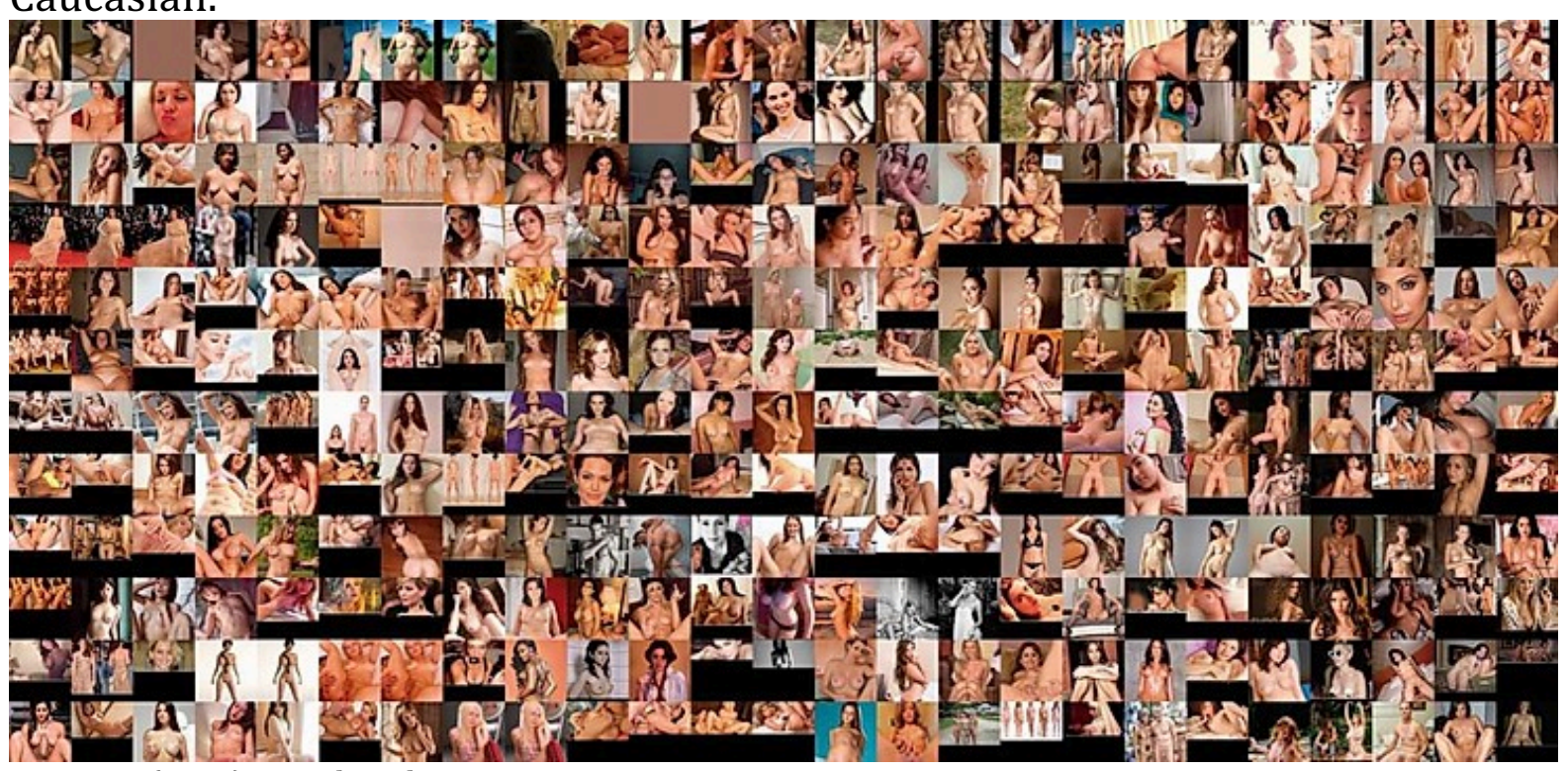

Figure 7: (2019) Canada. Ink on paper $100 \mathrm{~cm}$ x $48 \mathrm{~cm}$.

\section{Conclusion}

The significance of each of the video and photographic artefacts contributed distinct visualizations to the overriding research questions, and allowed the original 'scobo' research process to be visualized within the artefacts. Also, the videos and photoprints demonstrate how the project's art practice is informed through theoretical research, as the two artistic expressions of photography and video would not have existed if the project's first research had not been explored. In addition, the art practice allowed the search process and the results to be visualized in a format that revealed how the digital gaze in any language or culture is controlled through the software created by the corporation Google. In effect, the Digital Gaze project demonstrates how digital technology affects the representation of the nude through its electronic translation, and colonizes the digital sphere. Revealing that the male gaze is not tied to sexual preference, the digital gaze is a white, western, male gaze, promoted through free software. 
The video art piece Digital Gaze continues to explore the democracy of Google and the type of visual registry it provides. Explore the ongoing project in full here.

\section{References}

- Assange, J. (2014) When Google Met Wikileaks. London: OR Books.

- Assange, J. (2015) 'Google Is Not What It Seems', Wikileaks (n.d.). Available at: https://wikileaks.org/google-is-not-what-it-seems/.

- Bernays, E. (1928) Propaganda. New York: H. Liveright.

- Bernays, E. (1955) Engineering of Consent. Oklahoma: University of Oklahoma Press.

- Barthes, R. (1972) Mythologies. London: Cape.

- Barthes, R. (1974) S/Z. London: Cape.

- Barthes, R. (1977) Image-Music-Text. London: Fontana.

- Brandz (2018) (n.d.) Available at: http://brandz.com/charting/54.

- Couldry, N. and Mejias, Ulisies A. (2019) The Costs of Connection: How Data Is Colonizing Human Life and Appropriating It for Capitalism. Stanford: Stanford University Press.

- Foucault, M. (1977) Discipline and Punish: The Birth of the Prison. Trans. Alan Sheridan. New York: Vintage.

- Frayling, Christopher. (1993) Research in Art and Design. London: RCA

- Fuchs, C. (2008) Internet and Society: Social Theory in the Information Age. New York: Routledge.

- Fuchs, C. (2010) Labor in Informational Capitalism and on the Internet: The Information Society 26(3): 179-196.

- Fuchs, C. (2012) 'Google Capitalism', Triple-C (April 6) http://www.triple-c.at

- http://www.triple-c.at/index.php/tripleC/article/view/304/330. Garber, M. (2013) 'How to Catch a Liar on the Internet', The Atlantic (n.d.). Available at:

http://www.theatlantic.com/magazine/archive/2013/09/the-waywe-lie-now/309431/

- Google. (2018) Available at: http://www.google.com/intl/en/about/company/.

- Hern, A. (2018) 'Google Working on Censored Search Engine for China', The Guardian (May 3) Available at: https://www.theguardian.com/world/2018/aug/02/googleworking-on-censored-search-engine-forchina?CMP=Share_iOSApp_Other.

- Johnson, B. and Katz, I. (2010) 'Google co-founder Sergey Brin urges US to act over China web censorship', The Guardian (February 14). Available at: 
https://www.theguardian.com/technology/2010/mar/24/googlechina-sergey-brin-censorship.

- Jones, C. (2019) 'Racism and Classism in Mexican Advertising', in Meanings \& Co. Numanities: Arts and Humanities in Progress, Vol 6, edited by Olteanu A., Stables A., Borţun D. Cham: Springer.

- Lyons, D. (2015) 'Five myths about Google,' The Washington Post (March 10). Available at:

http://www.washingtonpost.com/opinions/five-myths-aboutgoogle/2015/03/20/a22bb30e-ce61-11e4-8a46-

b1dc9be5a8ff_story.html.

- McFarland, M. (2015) 'Google’s artificial intelligence breakthrough may have a huge impact on self-driving cars and much more', The Washington Post (Feb 25). Available at:

http://www.washingtonpost.com/blogs/innovations/wp/2015/02/ 25/googles-artificial-intelligence-breakthrough-may-have-a-hugeimpact-on-self-driving-cars-and-much-more/.

- Stevens, D. (2015) 'Chambers and Google Among Top Lobbying Spenders in First Quarter of 2015', Maplight (April 21). Available at: http://maplight.org/content/chamber-and-google-among-toplobbying-spenders-in-first-quarter-of-2015.

- McLuhan, M. (1967) The Medium is the Message. New York: Mentor.

- Mulvey, L. (1975) 'Visual Pleasure and Narrative Cinema', Screen 16(3) (Autumn): 6-18.

- Snowden, E. (2015) 'Snowden Surveillance Archive', Snowden Archive (n.d.). Available at: https://snowdenarchive.cjfe.org.

- Sturken, M. and Cartwright, L. (2009) Practices of Looking: An Introduction to Visual Culture. Oxford: Oxford University Press.

- Smythe, DW. (1981/2006) 'On the Audience Commodity and Its Work', in Media and Cultural Studies, edited by Meenakshi G. Durham and Douglas Kellner, 230-256. Malden: Blackwell.

- Thompson, A. (2017) 'Google's Mission Statement and Vision Statement (An Analysis', Panmore. (February 13). Available at: http://panmore.com/google-vision-statement-mission-statement.

- Toffler, A. (1980). The Third Wave. New York: Bantam.

- Tyler, J. (2018) 'The Ten Most Valuable Brands in 2018)', Inc. (n.d.). Available at: https://www.inc.com/business-insider/amazongoogle-most-valuable-brands-brand-finance-2018.html.

- Welch, D. (2013) Propaganda: Power and Persuasion. London: The British Library. 